\title{
A clinician's guide to recurrent isolated sleep paralysis
}

\author{
This article was published in the following Dove Press journal: \\ Neuropsychiatric Disease and Treatment \\ 19 July 2016 \\ Number of times this article has been viewed
}

\author{
Brian A Sharpless \\ Clinical Psychology Program, \\ American School of Professional \\ Psychology at Argosy University, \\ Washington DC, Arlington, VA, USA
}

Correspondence: Brian A Sharpless Clinical Psychology Program, American School of Professional Psychology at Argosy University, 1550 Wilson Boulevard, Suite 724, Arlington, VA 22209, USA

Tel +l 7035265833

Email basharpless@gmail.com

\begin{abstract}
This review summarizes the empirical and clinical literature on sleep paralysis most relevant to practitioners. During episodes of sleep paralysis, the sufferer awakens to rapid eye movement sleep-based atonia combined with conscious awareness. This is usually a frightening event often accompanied by vivid, waking dreams (ie, hallucinations). When sleep paralysis occurs independently of narcolepsy and other medical conditions, it is termed "isolated" sleep paralysis. Although the more specific diagnostic syndrome of "recurrent isolated sleep paralysis" is a recognized sleep-wake disorder, it is not widely known to nonsleep specialists. This is likely due to the unusual nature of the condition, patient reluctance to disclose episodes for fear of embarrassment, and a lack of training during medical residencies and graduate education. In fact, a growing literature base has accrued on the prevalence, risk factors, and clinical impact of this condition, and a number of assessment instruments are currently available in both self-report and interview formats. After discussing these and providing suggestions for accurate diagnosis, differential diagnosis, and patient selection, the available treatment options are discussed. These consist of both pharmacological and psychotherapeutic interventions which, although promising, require more empirical support and larger, well-controlled trials.
\end{abstract}

Keywords: sleep disorder, rapid eye movement, hallucinations, parasomnia, sleep-wake disorders, narcolepsy

\section{Introduction}

Sleep paralysis (SP) occurs when rapid eye movement (REM)-based atonia perseverates into wakefulness. ${ }^{1}$ Most individuals with SP also experience dream activity during the conscious paralysis that is vivid, multisensorial, and often negatively valenced. The combination of atonia and waking nightmares makes SP a very unpleasant experience for most people and the one that may not be easily understood. Patients may instead use other nonmedical explanations to make sense of it. Perhaps not surprisingly, SP has been thought to have a role in the genesis and/or maintenance of many supernatural beliefs (eg, nocturnal alien abductions and demonic attacks) in individuals with otherwise intact reality testing. ${ }^{2,3}$

Though noted by physicians and other scholars since the ancient Greeks, SP only recently began receiving attention from nonsleep specialists. This was partly due to the publication of books aimed at a broader readership, ${ }^{4}$ popular films on SP, ${ }^{5,6}$ and attention from the popular press. ${ }^{7}$ This increased public interest, partly due to SP's provocative paranormal connections, helped stimulate more empirical work. Indeed, the past decade has witnessed a number of important developments in our understanding of this phenomenon.

However, due to several factors, the clinical ramifications of SP remain relatively unknown to many practitioners, and it is neither routinely assessed 
nor treated in clinical practice. Therefore, the purpose of the present article is to conveniently summarize what is known about SP and the information most relevant to clinicians.

\section{Prevalence rate}

SP is surprisingly common. However, determining accurate prevalence rates is complicated by the fact that individual research studies often differ in their operationalization of SP and/or the specific measurements used for assessment (ie, questionnaires or clinical interviews). A recent systematic review of the literature (using a priori selection criteria) aggregated data from 35 empirical studies $(\mathrm{N}=36,533$ subjects) and found that $7.6 \%$ of the general population experienced at least one SP episode over the course of their life. ${ }^{8}$ Higher lifetime prevalence rates were found in students (28.3\%) and psychiatric patients $(31.9 \%)$, with females experiencing SP slightly more often than males. Interestingly, rates in non-Whites were higher than in Whites, but the magnitude of difference was less than many scholars would likely predict.

Rates of recurrent SP have been difficult to ascertain due to differences in definition across time. This problem is even more acute when attempting to determine rates of isolated SP (ie, SP not occurring in the context of narcolepsy, substance use, or other disorders) and recurrent isolated SP (RISP). Although narcolepsy is a rare condition (eg, prevalence rate $=0.0005^{9}$ ), the fact that it is so infrequently assessed in SP studies limits diagnostic precision.

\section{Risk factors for SP and isolated SP}

In addition to the aforementioned demographic variables associated with SP, other risk factors have been identified. Several medical conditions associated with SP are presented in Table 1.

\section{Sleep factors}

Perhaps not surprisingly, the presence of poor sleep and/or sleep disruption is associated with SP. ${ }^{10,11} \mathrm{SP}$ is common in shift workers ${ }^{12}$ and is most likely to occur when individuals

Table I Sleep paralysis and associated medical conditions

\begin{tabular}{ll}
\hline Condition & References \\
\hline Hypertension & 53 \\
Idiopathic hypersomnia & 54,55 \\
Insufficient sleep syndrome & 56 \\
Narcolepsy & 56 \\
Obstructive sleep apnea & 57 \\
Alcohol use & 10 \\
Wilson's disease & 58 \\
\hline
\end{tabular}

sleep in a supine position. ${ }^{13}$ Recent work has also linked SP to exploding head syndrome, another potentially frightening parasomnia. ${ }^{14}$

\section{Diagnostic and symptomatic factors}

Although psychiatric comorbidity, in general, has been associated with SP, ${ }^{15}$ there may be more specific diagnostic patterns. The most well established of these is the finding that trauma histories and posttraumatic stress disorder (PTSD) are common in those with SP. ${ }^{15-18}$ Furthermore, anxiety sensitivity, often conceptualized as a fear of the consequences of cognitive and somatic manifestations of anxiety, is elevated in people with $\mathrm{SP}^{15,19}$ and, as in panic disorder, has been hypothesized to be an etiological factor. ${ }^{2}$ More specifically, panic disorder, ${ }^{20}$ generalized anxiety disorder, ${ }^{21}$ death anxiety, ${ }^{22}$ and social anxiety $^{23}$ are frequent symptomatic accompaniments to SP. It is important to note that the causality of these relationships has yet to be determined. Thus, it is currently unclear whether PTSD actually causes SP or if the relationship is instead mediated by the sleep disruptions and hypervigilance so commonly found in PTSD symptomatology.

\section{Personality factors}

Certain personality traits may also be risk factors. For instance, higher levels of dissociation, ${ }^{24}$ imaginativeness, ${ }^{25}$ and beliefs in the paranormal/supernatural ${ }^{19}$ have been linked to SP. As with PTSD, the causal links between these personality traits and SP are unclear. Are those with paranormal beliefs more likely to have SP or those with SP more likely to have subsequent paranormal beliefs? A bidirectional causality is likely in effect.

\section{Diagnosing RISP}

At present, RISP is recognized as a formal diagnosis (G47.51) in the International Classification of Sleep Disorders (ICSD)-3, ${ }^{1}$ but lacks a diagnostic code in both the tenth edition of the International Statistical Classification of Diseases and Related Health Problems ${ }^{26}$ and the fifth edition of Diagnostic and Statistical Manual of Mental Disorders (DSM-5). ${ }^{27}$ However, RISP can be coded as an unspecified sleep-wake disorder (307.40) or other specified sleep-wake disorder (307.49).

\section{Diagnosing RISP}

Given that only some clinicians have been trained to diagnose RISP, a three-part procedure is recommended. Additional information on diagnosing SP and RISP can be found in Sharpless and Doghramji. ${ }^{2}$ 


\section{Establish the presence of isolated SP episodes}

Much like the relationship between panic attacks and panic disorder, individual SP episodes are not diagnosable on their own, but are required in order to establish the diagnostic entity of RISP. Isolated SP episodes are characterized by muscle atonia upon sleep onset or offset. ${ }^{1}$ Eye movements are intact and there may be some control over respiration, but feelings of suffocation are common. ${ }^{28}$ Episodes are usually brief (usually seconds to 20 minutes) with a mean duration of 6 minutes. ${ }^{29}$ In order to qualify as "isolated" SP, episodes should not be better explained by other sleep disorders (eg, narcolepsy), medication effects, or other substances. Hallucinations are often present during episodes, but are not necessary for a diagnosis.

\section{Establish the presence of RISP}

Diagnosis of the "syndrome" of RISP is not based upon any formal medical tests (eg, polysomnography), but upon structured and semistructured clinical interviews and/ or questionnaires. The former are preferred due to the oftentimes-confusing phenomenology of clinical presentations and the necessity for differential diagnosis. Thus, it is recommended that any assessment of RISP be made within the broader diagnostic context of other psychiatric conditions (eg, using the Structured Clinical Interview for DSM-5 Disorders) ${ }^{30}$

As per the current ICSD- $3^{1}$ criteria, RISP consists of multiple episodes of isolated SP that are associated with clinically significant distress (eg, anxiety and/or fear related to the bedroom/sleep). It is worth noting that ICSD criteria do not include frequency thresholds or clinically significant impairment, but these can be found in a prior, more specific set of diagnostic criteria developed for use in clinical trials. ${ }^{15}$ These criteria for "fearful" RISP require clinically significant fear during episodes and at least two episodes in the past 6 months.

Regardless of which clinical criteria are used, diagnosis requires some degree of RISP frequency as well as the presence of clinical distress and/or interference. As noted previously, distress during episodes is quite common, given the characteristic atonia and the possible presence of hallucinations and breathing difficulties. ${ }^{31}$ However, periepisode distress alone would not warrant diagnosis any more than panic attack distress would warrant a diagnosis of panic disorder. Common examples of distress/interference as a result of RISP episodes include 1) catastrophic worries about the potential implications of episodes (eg, "I'm going crazy", "the paralysis will someday be permanent"19); 2) avoidance behaviors (eg, sleep, bedroom setting ${ }^{32}$ ); and
3) other negative sequelae (eg, shame, embarrassment, daytime sleepiness, pronounced postepisode distress ${ }^{15,21,33}$ ).

A number of measures of SP are available to facilitate diagnosis. ${ }^{2}$ The most thorough clinician-administered interview is the "Fearful Isolated Sleep Paralysis Interview", ${ }^{2,15}$ A much briefer option would be the isolated SP module of the "Duke Structured Interview for Sleep Disorders", ${ }^{34}$ but some modification would be needed in order to assess all the current ICSD-3 criteria. Good questionnaire options for the assessment of SP include the "Unusual Sleep Experiences Questionnaire", 35 "Waterloo Unusual Sleep Experiences Questionnaire", ${ }^{28}$ or "Munich Parasomnia Screening". ${ }^{36}$

\section{Rule out competing diagnoses}

Depending upon patient presentation, overall health, and the history of previous conditions, differential diagnosis of the medical conditions listed in Table 1 is recommended. . $^{2,37}$ Clinicians should also rule out focal epileptic seizures, atonic seizures, cataplexy, various types of familial periodic paralysis (eg, Andersen-Tawil syndrome), and transient compression neuropathies.

Special mention should be made of differentiating RISP from narcolepsy. These conditions obviously display overlap, as SP episodes are a core feature of RISP and an associated feature of narcolepsy. Indeed, until the publication of DSM-5, ${ }^{27} \mathrm{SP}$ was specifically listed in the narcolepsy criteria. $\mathrm{SP}$ is also a core component of the narcoleptic tetrad. Thus, when patients present with SP, determining whether or not it is actually part of the more serious condition of narcolepsy is crucial. RISP can often be readily distinguished from narcolepsy on the basis of clinical interview assessing for: 1) the presence of cataplexy, a core feature of narcolepsy and 2) the presence of excessive daytime sleepiness (which, admittedly, can occur in more serious cases of RISP if there is significant sleep disruption and/or sleep avoidance behaviors). Polysomnography (including multiple sleep latency testing) can also be used if diagnostic uncertainty remains, as the objective data for the two conditions are quite different. $^{2}$

Recommendations for differentiating RISP from other psychiatric conditions can be found in Table 2. As noted earlier, unfamiliarity with the typical presentation of RISP may make differential diagnosis difficult. It is also important to note that psychotic experiences are fairly common in the general population. ${ }^{38}$ However, these should be fairly easy to differentiate from RISP phenomena due to their timing (viz, RISP hallucinations only occur during sleep-wake or wake-sleep transitions) and possibly their degree of narrative elaboration. 
Table 2 Differential diagnosis of recurrent isolated sleep paralysis from other conditions ${ }^{\mathrm{a}}$

\begin{tabular}{|c|c|}
\hline Condition & Differences from sleep paralysis \\
\hline $\begin{array}{l}\text { Exploding Head Syndrome } \\
\text { (EHS) }\end{array}$ & $\begin{array}{l}\text { EHS and SP are both potentially frightening parasomnias. The auditory (bangs, explosions) and visual (light flashes) } \\
\text { hallucinations of EHS are usually briefer (often I second or less) than SP hallucinations, always loud/jarring, and } \\
\text { undifferentiated (ie, not recognizable speech or part of a developed narrative); no paralysis occurs during EHS and } \\
\text { conscious awareness of surroundings is absent }\end{array}$ \\
\hline Nightmare disorder (ND) & $\begin{array}{l}\text { ND and SP are both REM-based parasomnias. The conscious awareness of one's surroundings and atonia is missing in } \\
\text { ND; dream imagery, though common in SP, need not be present for diagnosis, but is required for ND; unlike ND, } \\
\text { SP hallucinations are not always negatively valenced (but usually are) }\end{array}$ \\
\hline Sleep/night terrors (STs) & $\begin{array}{l}\text { STs and SP are both potentially frightening parasomnias. STs are non-REM based and lack awareness to surroundings; } \\
\text { dream imagery in STs, if present at all, is quite impoverished; characteristic screams during STs are not possible during } \\
\text { SP; attempts to comfort SP sufferers often result in a resolution of the episode, whereas this is not the case with STs }\end{array}$ \\
\hline $\begin{array}{l}\text { Nocturnal panic attacks } \\
\text { (NPAs) }\end{array}$ & $\begin{array}{l}\text { NPAs and SP both involve fear and acute distress. NPAs lack paralysis and dream imagery (ie, they are non-REM based); } \\
\text { NPAs are unexpected, acute, and scary, whereas fear in SP is often secondary to the paralysis/hallucinations }\end{array}$ \\
\hline $\begin{array}{l}\text { Posttraumatic stress } \\
\text { disorder (PTSD) }\end{array}$ & $\begin{array}{l}\text { PTSD and SP often include scary imagery and anxiety. PTSD flashbacks, though often containing vivid and frightening } \\
\text { images, are not usually just limited to sleep-wake transitions; any hypervigilance in SP is not as pervasive as in PTSD; } \\
\text { paralysis in PTSD is usually a subjective feeling or misperception during flashbacks, not an actual physical limitation; } \\
\text { images during flashbacks are related to the offending trauma(s) }\end{array}$ \\
\hline $\begin{array}{l}\text { Schizophrenia and other } \\
\text { psychotic disorders }\end{array}$ & $\begin{array}{l}\text { Psychotic disorders and SP often share disturbing and unwanted hallucinations. However, hallucinations during SP are } \\
\text { limited to sleep-wake transitions and gross reality testing is otherwise intact }\end{array}$ \\
\hline
\end{tabular}

Note: adapted from Sharpless and Doghramji. ${ }^{2}$

Abbreviations: SP, sleep paralysis; REM, rapid eye movement.

\section{Treatment of SP}

The ability of clinicians to make well-informed and prescriptive treatment decisions is currently hampered by the fact that not a single randomized controlled trial has yet been conducted for RISP. Thus, the recommendations below are based upon studies of narcolepsy, small case studies, clinical lore, and logical deductions from the basic research findings on SP and RISP. Fortunately, there are several promising psychopharmacological and psychotherapeutic approaches to treatment.

\section{Patient appropriateness}

The most basic question clinicians need to consider is whether or not treatment is actually warranted for their patients with SP. The majority of sufferers do not experience clinically significant distress and/or impairment. In the two studies that have assessed clinical impacts of SP to date, $43.6 \%$ of patients with isolated SP derived from a clinical sample ${ }^{15}$ and $15.4 \%$ of those with isolated SP in a student sample ${ }^{39}$ met the clinical distress/impairment criterion. However, even in cases of significant distress, very few individuals seek out treatment for RISP due to several reasons (eg, embarrassment ${ }^{2}$ ). In line with this, clinicians and patients need to determine if the costs of treatment in terms of money, time, and/or potential side effects are justified by the amount of suffering.

\section{Psychopharmacological options}

A number of pharmacological agents have been utilized to treat SP, often in the context of narcolepsy. Unfortunately, the assessment of SP and the particular nature of the outcome measures are either inconsistent across studies or not well defined.

The most commonly used agents are tricyclic antidepressants and selective serotonin reuptake inhibitors. Their hypothesized mechanism of action is the suppression of REM sleep. They are commonly used in the treatment of other symptoms of narcolepsy as well. Regarding the tricyclics, clomipramine (25-50 mg qd), imipramine (25-150 mg qd), protriptyline (10-40 mg), and desmethylimipramine (25-150 mg qd) have all been reported to reduce SP..$^{40-42}$ In one case reported by Koran and Raghavan, ${ }^{43}$ use of the tetracylic agent maprotiline (100-150 mg qd) surprisingly led to an increase in SP. Selective serotonin reuptake inhibitors such as fluoxetine $(40-80 \mathrm{mg} \mathrm{qd})^{43}$ and femoxetine $(600 \mathrm{mg})^{44}$ have been effectively utilized. The latter agent, not currently available in the US but approved for use in Europe, was tested in a doubleblinded crossover study on ten patients with narcolepsy. Femoxetine reduced episodes in the seven patients suffering from SP more than placebo. ${ }^{44}$ Finally, it may be important to note that the selective norepinephrine reuptake inhibitor viloxazine (300 $\mathrm{mg}$ bid) was used in an open multicenter trial, but SP results did not significantly differ from placebo. ${ }^{42}$

One of the more well-studied pharmacological agents for SP is sodium oxybate (gamma-hydroxybutyric acid [GHB]). Although results are inconsistent across studies of narcoleptic patients (possibly due to a lack of power to detect significant clinical effects), GHB (3-9 g) may lead to reduction in SP episodes. ${ }^{45,46}$ 
In summary, much more work is needed in this area. The lack of systematic research for RISP should lead to a cautious interpretation of the extremely limited empirical findings. Therefore, clinicians are encouraged to consider typical factors when prescribing, such as side effect profiles (eg, activation vs sedation) and cost. ${ }^{2}$ In the case of GHB, a past or current history of substance abuse may be a prudent consideration. Patient education may be particularly important with RISP, as REM rebound effects have been reported by patients when abruptly discontinuing medications or even when commencing continuous positive airway pressure for obstructive sleep apnea. It may also be important to note that it is currently unknown whether or not SP and isolated SP respond similarly to pharmacological treatments or if there are differential efficacies.

\section{Psychotherapeutic options}

\section{Psychoeducation and reassurance}

The most basic therapy a clinician can provide is simple reassurance and education about the nature of RISP. The fact that individuals often report feelings of shame or misattributions of the causes for episodes (eg, going "crazy", paranormal events) has been discussed frequently in the literature. ${ }^{21,47}$ Therefore, the normalization of RISP by a concerned professional, even in the absence of other, more formal treatment regimens, could eventuate in a positive clinical impact. ${ }^{2}$

\section{Sleep hygiene and insomnia treatment}

Given that a proximal cause of RISP episodes is fragmented and/or disrupted sleep, simple alterations to sleep behavior may be effective. Instructions on various sleep hygiene techniques (eg, going to sleep and waking up at the same time each day, no use of alcohol or caffeine before bed, and other techniques listed in Edinger and $\mathrm{Carney}^{48}$ ) may serve as preventative measures. SP-specific instructions (eg, the avoidance of sleep in a supine or prone position) are also recommended. Should patients with RISP also have a comorbid sleep problem such as an insomnia disorder, a dedicated treatment ${ }^{49}$ may be helpful.

\section{Cognitive behavioral therapy}

Sharpless and Doghramji ${ }^{2}$ published the first treatment manual for RISP. This short-term (ie, five-session) treatment, "Cognitive-Behavioral Therapy for Isolated Sleep Paralysis", was derived from earlier work on SP, ${ }^{50,51}$ validated insomnia treatments, and an empirical investigation into the ways that SP sufferers attempt to both prevent and disrupt episodes. ${ }^{39}$ In order to facilitate research, an adherence measure was included, but this manual has yet to be empirically validated.
Cognitive-Behavioral Therapy for Isolated Sleep Paralysis includes SP-specific sleep hygiene, relaxation techniques for use during RISP episodes, in vivo episode disruption techniques, ways to cope with frightening hallucinations, disputation of catastrophic thoughts, and imaginary rehearsal of successful resolutions to RISP episodes.

A similar psychotherapeutic approach using meditation and relaxation was recently published..$^{52}$ This treatment was applied to two cases that received therapy remotely, with positive preliminary results reported.

\section{Conclusion and future directions}

In conclusion, although there are a number of options available for the assessment and treatment of RISP, more research is needed before a "gold standard" assessment instrument emerges and thoughtful, empirically supported treatment recommendations can be made. This is perhaps not surprising, given the somewhat unusual nature of the condition as well as the status of the scientific literature. Therefore, a careful observation of responses to these novel treatments and responsiveness to the particularities of RISP patients is clearly required. Although well-controlled trials are needed, the RISP literature could also be advanced through carefully conducted case studies and open trials, so long as sufficient detail is provided to permit replication.

\section{Disclosure}

The author reports no conflicts of interest in this work.

\section{References}

1. American Academy of Sleep Medicine. International Classification of Sleep Disorders: Diagnostic and Coding Manual. 3 ed. Darien, IL: American Academy of Sleep Medicine; 2014.

2. Sharpless BA, Doghramji K. Sleep Paralysis: Historical, Psychological, and Medical Perspectives. New York, NY: Oxford University Press; 2015.

3. French CC, Santomauro J. Something wicked this way comes: causes and interpretations of sleep paralysis. In: Tall Tales about the Mind \& Brain: Separating Fact from Fiction. New York, NY: Oxford University Press; 2007:380-398.

4. Hufford D. The Terror that Comes in the Night: An Experience-Centred Study of Supernatural Assault Traditions. Philadelphia, PA: University of Pennsylvania Press; 1982.

5. MacKinnon C. Devil in the Room; 2013.

6. Ascher R. The Nightmare; 2015.

7. Grant E. Secret history of UFOs. National Geographic Television; 2012.

8. Sharpless BA, Barber JP. Lifetime prevalence rates of sleep paralysis: a systematic review. Sleep Med Rev. 2011;15(5):311-315.

9. Pelayo R, Lopes MC. Narcolepsy. In: Lee-Chiong TL, editor. Sleep Medicine Essentials. Hoboken, NJ: Wiley-Blackwell; 2009:47-51.

10. Shengli M, Wu T, Pi G. Sleep paralysis in Chinese adolescents: a representative survey. Sleep Biol Rhythms. 2014;12:46-52.

11. Takeuchi T, Fukuda K, Sasaki Y, Inugami M, Murphy TI. Factors related to the occurrence of isolated sleep paralysis elicited during a multi-phasic sleep-wake schedule. Sleep. 2002;25(1):89-96.

12. Kotorii T, Kotorii T, Uchimura N, et al. Questionnaire relating to sleep paralysis. Psychiatry Clin Neurosci. 2001;55(3):265-266. 
13. Cheyne JA. Situational factors affecting sleep paralysis and associated hallucinations: position and timing effects. J Sleep Res. 2002; 11(2):169-177.

14. Sharpless BA. Exploding head syndrome is common in college students. J Sleep Res. 2015;24(4):447-449.

15. Sharpless BA, McCarthy KS, Chambless DL, Milrod BL, Khalsa SR, Barber JP. Isolated sleep paralysis and fearful isolated sleep paralysis in outpatients with panic attacks. J Clin Psychol. 2010;66(12): 1292-1306

16. Denis D, French CC, Rowe R, et al. A twin and molecular genetics study of sleep paralysis and associated factors. J Sleep Res. 2015;24(4): 438-446.

17. Young E, Xiong S, Finn L, Young T. Unique sleep disorders profile of a population-based sample of 747 Hmong immigrants in Wisconsin. Soc Sci Med. 2013;79:57-65.

18. Ohayon MM, Shapiro CM. Sleep disturbances and psychiatric disorders associated with posttraumatic stress disorder in the general population. Compr Psychiatry. 2000;41(6):469-478.

19. Ramsawh HJ, Raffa SD, White KS, Barlow DH. Risk factors for isolated sleep paralysis in an African American sample: a preliminary study. Behav Ther. 2008;39(4):386-397.

20. Yeung A, Xu Y, Chang DF. Prevalence and illness beliefs of sleep paralysis among Chinese psychiatric patients in China and the United States. Transcult Psychiatry. 2005;42(1):135-143.

21. Otto MW, Simon NM, Powers M, Hinton D, Zalta AK, Pollack MH. Rates of isolated sleep paralysis in outpatients with anxiety disorders. $J$ Anxiety Disord. 2006;20(5):687-693.

22. Arikawa H, Templer DI, Brown R, Cannon WG, Thomas-Dodson S. The structure and correlates of Kanshibari. J Psychol. 1999;133(4): 369-375.

23. Simard V, Nielsen TA. Sleep paralysis-associated sensed presence as a possible manifestation of social anxiety. Dreaming. 2005;15(4): 245-260.

24. McNally RJ, Clancy SA. Sleep paralysis, sexual abuse, and space alien abduction. Transcult Psychiatry. 2005;42(1):113-122.

25. Spanos NP, McNulty SA, DuBreuil SC, Pires M. The frequency and correlates of sleep paralysis in a university sample. J Res Pers. 1995; 29(3):285-305.

26. World Health Organization. International Statistical Classification of Diseases and Related Health Problems. 10th ed. Geneva, Switzerland: World Health Organization; 2008.

27. American Psychiatric Association. Diagnostic and Statistical Manual of Mental Disorders: DSM-5. 5th ed. Arlington, VA: American Psychiatric Association; 2013.

28. Cheyne JA, Newby-Clark IR, Rueffer SD. Relations among hypnagogic and hypnopompic experiences associated with sleep paralysis. J Sleep Res. 1999;8(4):313-317.

29. Hinton DE, Pich V, Chhean D, Pollack MH. The ghost pushes you down: sleep paralysis-type panic attacks in a Khmer refugee population. Transcult Psychiatry. 2005;42(1):46-77.

30. First MB, Williams JBW, Karg RS, Spitzer RL. Structured Clinical Interview for DSM-5 Disorders: Patient Edition. New York: Biometrics Research Department; 2014.

31. Sharpless BA. Isolated sleep paralysis and affect. In: Babson K, Feldner M, editors. Sleep and Affect. New York: Elsevier; 2016:181-199.

32. Alvaro L. Hallucinations and pathological visual perceptions in Maupassant's fantastical short stories - a neurological approach. J Hist Neurosci. 2005;14:100-115.

33. Jimenez-Genchi A, Avila-Rodriguez VM, Sanchez-Rojas F, Terrez BE, Nenclares-Portocarrero A. Sleep paralysis in adolescents: the 'a dead body climbed on top of me' phenomenon in Mexico. Psychiatry Clin Neurosci. 2009;63(4):546-549.

34. Edinger JD, Bonnet MH, Bootzin RR, et al. Derivation of research diagnostic criteria for insomnia: report of an American Academy of Sleep Medicine work group. Sleep. 2004;27(8):1567-1596.
35. Paradis C, Friedman S, Hinton DE, McNally RJ, Solomon LZ, Lyons KA. The assessment of the phenomenology of sleep paralysis: the unusual sleep experiences questionnaire (USEQ). CNS Neurosci Ther. 2009;15(3):220-226.

36. Fulda S, Hornyak M, Muller K, Cerny L, Beitinger PA, Wetter TC. Development and validation of the Munich parasomnia screening (MUPS): a questionnaire for parasomnias and nocturnal behaviors. Somnologie. 2008;12:56-65.

37. Sharpless BA, Denis D. Isolated sleep paralysis. In: Sharpless BA, editor. Unusual and Rare Psychological Disorders. New York: Oxford University Press; in press.

38. McGrath JJ, Saha S, Al-Hamzawi A, et al. Psychotic experiences in the general population: a cross-national analysis based on 31,261 respondents from 18 countries. JAMA Psychiatry. 2015;72(7): 697-705.

39. Sharpless BA, Grom JL. Isolated sleep paralysis: fear, prevention, and disruption. Behav Sleep Med. 2016;14(2):134-139.

40. Hishikawa Y, Ida H, Nakai K, Kaneko Z. Treatment of narcolepsy with imipramine (tofranil) and desmethylimipramine (pertofran). J Neurol Sci. 1966;3(5):453-461.

41. Guilleminault C, Raynal D, Takahashi S, Carskadon M, Dement W. Evaluation of short-term and long-term treatment of the narcolepsy syndrome with clomipramine hydrochloride. Acta Neurol Scand. 1976; 54(1):71-87.

42. Mitler MM, Hajdukovic R, Erman M, Koziol JA. Narcolepsy. J Clin Neurophysiol. 1990;7(1):93-118.

43. Koran LM, Raghavan S. Fluoxetine for isolated sleep paralysis. Psychosomatics. 1993;34(2):184-187.

44. Schrader H, Kayed K, Bendixen Markset AC, Treidene HE. The treatment of accessory symptoms in narcolepsy: a double-blind cross-over study of a selective serotonin re-uptake inhibitor (femoxetine) versus placebo. Acta Neurol Scand. 1986;74(4):297-303.

45. Mamelak M, Black J, Montplaisir J, Ristanovic R. A pilot study on the effects of sodium oxybate on sleep architecture and daytime alertness in narcolepsy. Sleep. 2004;27(7):1327-1334.

46. The U.S. Xyrem Multicenter Study Group. A randomized, double blind, placebo-controlled multicenter trial comparing the effects of three doses of orally administered sodium oxybate with placebo for the treatment of narcolepsy. Sleep. 2002;25(1):42-49.

47. Neal AM, Rich LN, Smucker WD. The presence of panic disorder among African American hypertensives: A pilot study. J Black Psychol. 1994;20(1):29-35.

48. Edinger JD, Carney CE. Overcoming Insomnia: A Cognitive-Behavioral Therapy Approach. New York: Oxford University Press; 2008.

49. Perlis ML, Jungquist C, Smith MT, Posner D. Cognitive Behavioral Treatment of Insomnia A Session-by-Session Guide. New York, NY: Springer Science + Business Media, LLC; 2005.

50. Hinton DE, Hufford DJ, Kirmayer LJ. Culture and sleep paralysis. Transcult Psychiatry. 2005;42(1):5-10.

51. Hinton DE, Pich V, Chhean D, Pollack MH, McNally RJ. Sleep paralysis among Cambodian refugees: association with PTSD diagnosis and severity. Depress Anxiety. 2005;22(2):47-51.

52. Jalal B. How to make the ghosts in my bedroom disappear? Focusedattention meditation combined with muscle relaxation (MR therapy) a direct treatment intervention for sleep paralysis. Front Psychol. 2016;7:28

53. Bell CC, Hildreth CJ, Jenkins EJ, Carter C. The relationship of isolated sleep paralysis and panic disorder to hypertension. J Natl Med Assoc. 1988;80(3):289-294.

54. Anderson KN, Pilsworth S, Sharples LD, Smith IE, Shneerson JM. Idiopathic hypersomnia: A study of 77 cases. Sleep. 2007;30(10): 1274-1281.

55. Ali M, Auger RR, Slocumb NL, Morgenthaler TI. Idiopathic hypersomnia: clinical features and response to treatment. J Clin Sleep Med. 2009; 5(6):562-568 
56. American Academy of Sleep Medicine. International Classification of Sleep Disorders. Darien, IL: American Academy of Sleep Medicine; 2001.

57. Hsieh S, Lai C, Liu C, Lan S, Hsu C. Isolated sleep paralysis linked to impaired nocturnal sleep quality and health-related quality of life in Chinese-Taiwanese patients with obstructive sleep apnea. Qual Life Res. 2010;19(9):1265-1272.
58. Portala K, Westermark K, Ekselius L, Broman J. Sleep in patients with treated Wilson's disease: a questionnaire study. Nord J Psychiatry. 2002; 56(4):291-297.

\section{Publish your work in this journal}

Neuropsychiatric Disease and Treatment is an international, peerreviewed journal of clinical therapeutics and pharmacology focusing on concise rapid reporting of clinical or pre-clinical studies on a range of neuropsychiatric and neurological disorders. This journal is indexed on PubMed Central, the 'PsycINFO' database and CAS, and is the official journal of The International Neuropsychiatric Association (INA). The manuscript management system is completely online and includes a very quick and fair peer-review system, which is all easy to use. Visit http://www.dovepress.com/testimonials.php to read real quotes from published authors.

Submit your manuscript here: http://www.dovepress.com/neuropsychiatric-disease-and-treatment-journal 